\title{
When to remove the drainage catheter in patients with percutaneous cholecystostomy?
}

\author{
Sevcan Alkan Kayaoglu ${ }^{*}$ (D) Metin Tilki ${ }^{1}$
}

\begin{abstract}
SUMMARY
OBJECTIVE: The treatment for patients with acute calculous cholecystitis who have high surgical risk with percutaneous cholecystostomy instead of surgery is an appropriate alternative choice. The aim of this study was to examine the promising percutaneous cholecystostomy intervention to share our experiences about the duration of catheter that has yet to be determined.

METHODS: A total of 163 patients diagnosed with acute calculous cholecystitis and treated with percutaneous cholecystostomy between January 2011 and July 2020 were reviewed retrospectively. The Tokyo Guidelines 2018 were used to diagnose and grade patients with acute cholecystitis. RESULTS: The mean age was $71.81 \pm 12.81$ years. According to the Tokyo grading, 143 patients had grade 2 and 20 patients had grade 3 disease. The mean duration of catheter was $39.12 \pm 37$ (1-270) days. Minimal bile leakage into the peritoneum was noted in 3 (1.8\%) patients during the procedure. The rate of complications during follow-up of the patients who underwent percutaneous cholecystostomy was $6.9 \%$ ( $n=11$ ), and the most common complication was catheter dislocation. Cholecystectomy was performed in 33.1\% ( $n=54)$ of the patients at follow-up. Post-cholecystectomy complication rate was $12.9 \%$. At the follow-up, the rate of recurrent acute cholecystitis episodes was $5.5 \%$, while the mortality rate was $1.8 \%$. The length of follow-up was five years.

CONCLUSIONS: The rate of recurrence was significantly higher among the patients with catheter for $<21$ days. We recommend that the duration of catheter should be minimum 21 days in patients undergoing percutaneous cholecystostomy.

KEYWORDS: Acute cholecystitis. Cholecystostomy.
\end{abstract}

\section{INTRODUCTION}

Acute cholecystitis is one of the most common diseases in surgical clinics in developed countries ${ }^{1}$. According to the Tokyo Guidelines 2018 (TG18), percutaneous cholecystostomy (PC) can be performed in a selected group of grade 2 and three patients who are considered not being able to handle the high-risk surgery. However, the eligible patient selection for $\mathrm{PC}$ and the subsequent management of these patients in the clinic have not been clearly defined ${ }^{2}$. Patients with multiple comorbidities, late presentation to healthcare facility after the onset of symptoms, and unresponsive to antibiotic therapy are the candidates for $\mathrm{PC}^{3}$. Patients with high-grade disease according to the TG18 severity rating are associated with prolonged hospital stays and more common complications $s^{4}$. Surgical treatments tried to be minimized every passing $\mathrm{day}^{5}$. Our aim was to analyze the clinical follow-up of patients undergoing PC to determine the safe timing that can be recommended for the removal of the catheter by the algorithms to be created, thereby contributing to the development of treatment algorithms.

\section{METHODS}

This retrospective cohort study was conducted at the Haydarpasa Numune Training and Research Hospital, Istanbul, which is a tertiary care referral center. A total of 163 patients diagnosed with acute calculous cholecystitis and treated with PC between January 2011 and July 2020 were included. Upon the ethics committee approval ( $\mathrm{N}^{\circ}$. HNEAH-KAEK 2021/KK/5), the hospital database was used to review the patients who had an entry for the "PC" procedure. The Tokyo Criteria were used for the diagnosis of acute cholecystitis 4 . Inclusion criteria were as follows:

- Patients with grades 2-3 acute cholecystitis according to the TG18 criteria,

- Patients with acute cholecystitis presenting to the hospital more than $72 \mathrm{~h}$ after the onset of symptoms and/ or not clinically responding to intravenous (IV) antibiotic therapy within $48-72 \mathrm{~h}$.

- Exclusion criteria were as follows:

- Patients undergoing PC for biliary drainage due to reasons such as malignancy and bile duct strictures.

- Patients with acute acalculous cholecystitis.

${ }^{1}$ Haydarpasa Numune Training and Research Hospital, Department of General Surgery - Istanbul, Turkey.

${ }^{*}$ Corresponding author: sevcanalkan82@gmail.com

Conflicts of interest: the authors declare there is no conflicts of interest. Funding: none.

Received on August 22, 2021. Accepted on September 13, 2021. 
Routine abdominal ultrasonography was performed in all patients. PC was performed by an experienced radiologist under local anesthesia, using the Seldinger technique under ultrasound guidance by a transhepatic or transperitoneal approach. A culture antibiogram was tested using the bile samples collected from each patient as a routine during PC. Stasis enzymes, bilirubin, white blood cell (WBC) and C-reactive protein (CRP) values before PC, and WBC and CRP values at discharge after PC were recorded for all the patients. The time from the onset of symptoms (days), comorbidities, American Society of Anesthesiologists (ASA) scores, names of microorganisms in case of growth in the culture, the timing of drainage tube removal, the technique for tube placement, the presence/absence of recurrent acute calculous cholecystitis episodes (recurrence) after PC at the follow-up, the presence/absence of cholecystectomy, and complications were recorded. The length of follow-up was five years.

The IBM SPSS Statistics version 22 (IBM SPSS, Turkey) software package was used for the statistical analyses of the study data. The normality of the parameters was tested using the Shapiro-Wilk test. In addition to the descriptive statistical methods (mean, standard deviation, and frequency), the Mann-Whitney $U$ test was used to compare quantitative data and non-normally distributed parameters between two groups. A $p<0.05$ was considered statistically significant.

\section{RESULTS}

The mean length of hospital stay was $10.64 \pm 7.45$ days, and the mean time from the onset of complaints to presentation to healthcare facility was $3 \pm 1.09$ days. Of a total of 163 patients, $61.3 \%$ were males. The mean age was 71.81 years. There was at least one comorbidity, and mostly multiple comorbidities, in 153 of the patients. PC was performed by a transhepatic approach in $111(68.1 \%)$ patients and by a transperitoneal approach in the remaining patients. The most commonly used one was 8F $(71.8 \%)$ catheters in the procedure. General characteristics and comorbidities of the patients are presented in Table 1.

The most frequently administered IV antibiotic was ceftriaxone+metronidazole with a rate of $45.4 \%$. Antibiotic changes were made in 29 patients. A growth rate of $40.5 \%(n=66)$ was detected in the culture performed during the procedure, and the most common microorganism was Escherichia coli with a rate of $43.9 \%(n=29)$. In patients with recurrence, the duration of IV antibiotic use before the procedure was statistically significantly shorter than those without any recurrent episodes ( $\mathrm{p}=0.030$ and $\mathrm{p}<0.05$, respectively).

According to TG18, 143 patients had grade 2 disease and 20 patients had grade 3 disease. The ASA score was 3 or
Table 1. Distribution of general characteristics.

\begin{tabular}{|c|c|c|c|}
\hline & Mean \pm SD & Min-Max \\
\hline \multicolumn{2}{|l|}{ Age (years) } & $71.81 \pm 12.81$ & $32-96$ \\
\hline \multicolumn{2}{|c|}{$\begin{array}{l}\text { Length of hospital stay } \\
\text { (median) }\end{array}$} & $10.64 \pm 7.45(8)$ & $1-44$ \\
\hline \multicolumn{2}{|c|}{$\begin{array}{l}\text { Duration of complaints (days) } \\
\text { (median) }\end{array}$} & $3 \pm 1.09$ (3) & $1-10$ \\
\hline \multicolumn{2}{|c|}{ The day of hospital stay for PC } & $2.52 \pm 2.26(2)$ & $0-17$ \\
\hline \multicolumn{2}{|c|}{ Duration of catheter $(n=160)$} & $39.12 \pm 37(30)$ & $1-270$ \\
\hline \multicolumn{2}{|c|}{$\begin{array}{l}\text { Timing of cholecystectomy } \\
(n=54)\end{array}$} & $\begin{array}{c}72.33 \pm 61.61 \\
(55.5)\end{array}$ & $7-365$ \\
\hline & & $\mathbf{n}$ & $\%$ \\
\hline \multirow{2}{*}{ Sex } & Male & 100 & 61.3 \\
\hline & Female & 63 & 38.7 \\
\hline \multirow{3}{*}{ ASA } & 2 & 20 & 12.3 \\
\hline & 3 & 37 & 22.7 \\
\hline & 4 & 106 & 65 \\
\hline \multirow{2}{*}{ Tokyo grading } & 2 & 143 & 87.7 \\
\hline & 3 & 20 & 12.3 \\
\hline \multirow{2}{*}{ Comorbidities } & No & 10 & 6.1 \\
\hline & Yes & 153 & 93.9 \\
\hline
\end{tabular}

ASA:American Society of Anesthesiologists; PC: percutaneous cholecystostomy; SD: standard deviation.

4 in 143 patients and two in 20 patients. Cholecystectomy was performed in $54(33.1 \%)$ patients at follow-up, and the mean time from PC to cholecystectomy was $72.33 \pm 61.61$ days. Post-cholecystectomy complication rate was $12.9 \%$. Wound site infection was the most common complication (4/7). Two patients had postoperative bile leakage and were treated with Endoscopic Retrograde Cholangio-Pancreatography (ERCP). One patient was re-operated for intra-abdominal abscess. The perioperative duodenal injury that occurred in two patients was repaired primarily.

The PC is technically $100 \%$ successful. Minimal bile leakage into the peritoneum was noted in $3(1.8 \%)$ patients during the procedure. The rate of catheterization-related complications during follow-up of the patients was $6.9 \%(n=11)$; catheter revision was performed for the catheter dislocation in seven patients.

The timing of percutaneous cholecystostomy tube (PCT=percutaneous drainage tube) removal was 39.12 \pm 37 days, and three patients with failed recording of the exact catheter removal time were not included in the calculation. In our study, recurrent acute calculous cholecystitis at follow-up was considered recurrence and the recurrence rate was found to be 5.5\% (9/163) (Table 2). 
Table 2. Relationship between recurrence (acute cholecystitis episode) and parameters.

\begin{tabular}{|c|c|c|c|}
\hline & $\begin{array}{l}\text { Recurrence } \\
\text { Absent }\end{array}$ & $\begin{array}{l}\text { Recurrence } \\
\text { Present }\end{array}$ & p-value \\
\hline \multicolumn{4}{|c|}{ Duration of catheter } \\
\hline$<21$ & $36(23.4)$ & $6(66.7)$ & \multirow{2}{*}{0.004} \\
\hline$\geq 21$ & $118(76.6)$ & 3 (33.3) & \\
\hline \multicolumn{4}{|c|}{ Duration of catheter } \\
\hline$<100$ & $143(92.9)$ & $9(100)$ & \multirow{2}{*}{0.406} \\
\hline$\geq 100$ & $11(7.1)$ & $\mathrm{O}(0)$ & \\
\hline \multicolumn{4}{|c|}{ Duration of catheter } \\
\hline$<7$ & $9(5.8)$ & $\mathrm{O}(0)$ & \multirow{2}{*}{0.456} \\
\hline$\geq 7$ & $145(94.2)$ & $9(100)$ & \\
\hline \multicolumn{4}{|c|}{ Tokyo grading } \\
\hline 2 & $134(87)$ & $9(100)$ & \multirow{2}{*}{0.248} \\
\hline 3 & $20(13)$ & $\mathrm{O}(0)$ & \\
\hline \multicolumn{4}{|c|}{ Preoperative WBC (cells/ $\mu \mathrm{L}$ ) } \\
\hline$<18000$ & $104(67.5)$ & $5(55.6)$ & \multirow{2}{*}{0.458} \\
\hline$\geq 18000$ & $50(32.5)$ & $4(44.4)$ & \\
\hline \multicolumn{4}{|c|}{ Antibiotic resistance } \\
\hline No & $127(82.5)$ & $7(77.8)$ & \multirow{2}{*}{0.721} \\
\hline Yes & $27(17.5)$ & $2(22.2)$ & \\
\hline \multicolumn{4}{|c|}{ Positive growth culture } \\
\hline No & $90(58.4)$ & $7(77.8)$ & \multirow{2}{*}{0.251} \\
\hline Yes & $64(41.6)$ & $2(22.2)$ & \\
\hline
\end{tabular}

WBC: White blood cells. Bold values denote statistical significance at $p<0.05$.

There were no significant differences between cases with and without recurrences regarding CRP, duration of hospital stay, and WBC counts. The duration of PCT was statistically significantly shorter in patients with recurrent episodes than in those without any recurrent episodes $(\mathrm{p}=0.014)$. When the effect of catheter duration on recurrence was examined for 7, 21, and 100 days, there was a significant effect on recurrence only for the duration of $<21$ days $(\mathrm{p}=0.004)$ (Tables 2 and 3).

The mortality rate was $1.8 \%$ and the mortality was calculated for the postoperative 60 days. All three patients who died were at very high risk, had grade 3 disease, had an ASA score of 4 , and were directly admitted to intensive care unit upon presentation to the hospital.
Table 3. Comparison of duration of antibiotic use and duration of catheter between patients with and without recurrence.

\begin{tabular}{|c|c|c|c|}
\hline & \multicolumn{2}{|c|}{ Recurrence } & \multirow{3}{*}{ p-value } \\
\hline & No & Yes & \\
\hline & $\begin{array}{l}\text { Mean } \pm \text { SD } \\
\text { (median) }\end{array}$ & $\begin{array}{l}\text { Mean } \pm \text { SD } \\
\text { (median) }\end{array}$ & \\
\hline $\begin{array}{l}\text { Pre-PC duration of } \\
\text { intravenous antibiotic } \\
\text { use (days) }\end{array}$ & $\begin{array}{c}2.71 \pm 2.31 \\
(2)\end{array}$ & $1.56 \pm 1.33(1)$ & $0.030^{*}$ \\
\hline $\begin{array}{l}\text { Post-PC duration of } \\
\text { intravenous antibiotic } \\
\text { use (days) }\end{array}$ & $\begin{array}{c}7.62 \pm 5.05 \\
(6)\end{array}$ & $6.22 \pm 3.15(6)$ & 0.562 \\
\hline $\begin{array}{l}\text { Duration of catheter } \\
\text { (days) }\end{array}$ & $\begin{array}{c}39.12 \pm 37 \\
(30)\end{array}$ & $\begin{array}{c}21.89 \pm 16.8 \\
(16)\end{array}$ & $0.014^{*}$ \\
\hline
\end{tabular}

PC: percutaneous cholecystostomy; SD: standard deviation. *Mann-Whitney $U$ test, $p<0.05$. Bold values denote statistical significance at $p<0.05$.

\section{DISCUSSION}

The main treatment of patients with grade 1 acute cholecystitis is early laparoscopic cholecystectomy ${ }^{6}$. When patients with acute cholecystitis are treated conservatively, gallbladder and bile duct complications may develop in only $30 \%{ }^{7}$. We believe that PC is the most important weapon in nonsurgical treatment instead of cholecystectomy in selected grades 2 and three patients.

The most common microorganism was E. coli, and the growth rates were found to be consistent with the literature (growth rate of $29-54 \%$ in the literature) $)^{6,8}$. There was no significant difference in recurrence between patients with and without growth in their cultures. Despite the significantly shorter duration of preoperative IV antibiotic use in patients with recurrence than those without recurrence, there was growth in the bile cultures of only two (22.2\%) patients with recurrence, and Enterococcus faecium was isolated in both. We believe that further research with more recurrence cases is required to better understand or confirm this relationship.

In the study by Wise et al., the timing for the catheter tract formation was determined as 20 days ${ }^{9}$. Studies on the timing of tube removal in patients undergoing $\mathrm{PC}$ could not establish a clear relationship ${ }^{10,11}$. Bhatt et al. ${ }^{12}$ analyzed 145 patients and found no significant relationship between the duration of catheter and recurrent episodes. In this study, however, there was a significant number of patients with acute calculous cholecystitis and acalculous cholecystitis $(\mathrm{n}=47)$, and the mean duration of catheter was relatively long (mean: 57 days, 30-86 days) due to the presence of these patients and short durations of catheter could not be fully evaluated ${ }^{12}$. 
For patients with very high mortality and morbidity, some studies suggest permanent follow-up upon PC without cholecystectomy or follow-up with PCT until cholecystectomy ${ }^{13,14,15}$. Accordingly, our study also performed PCT immediately before or during cholecystectomy in 22 of 54 patients undergoing cholecystectomy. Regardless of cholecystectomy, the catheter remained for a long time in some patients, exceeding 100 days in 11 patients. All of these patients had multiple morbidities, had a high ASA score, did not accept surgery, or were planned to be followed up by the clinician without surgery due to the risks, and none of them had recurrence. Of course, living with a tube for a long time will negatively affect the quality of life.

The study by Bundy et al. on 324 patients reported similar culture growth rates (39.5\%) to our study, while the mean duration of catheter was 89 days, and recurrence was not evaluated. The mortality rate was higher compared to our study $(6.8 \%)$. However, this study included patients with acalculous cholecystitis and calculated long-term mortality ${ }^{16}$.

While Hsieh et al. found that PCT remained for $>2$ weeks and high CRP levels were associated with early recurrence, our study showed that early PCT removal have a significant relationship with recurrence, but no significant relationship between high CRP levels and recurrence. This study recommended the removal of the PC tube immediately after recovery from acute illness. Although recurrence rates were similar to our study, the said study calculated recurrence for a two-month period. Furthermore, since the mean duration of catheter was relatively short, it did not provide information on long-term outcomes. (Recurrence was observed in $11 / 126$ patients, the duration of catheter was $16.6 \pm 14.00)^{17}$. Another cohort study found the timing of $<7$ days for catheter removal to be associated with recurrent episodes, whereas our study could not establish such relationship ${ }^{18}$.

\section{REFERENCES}

1. Elwood DR. Cholecystitis. Surg Clin North Am. 2008;88(6):124152,VIII. https://doi.org/10.1016/j.suc.2008.07.008

2. Okamoto K, Suzuki K, Takada T, Strasberg SM, Asbun HJ, Endo I, et al. Tokyo Guidelines 2018: flowchart for the management of acute cholecystitis. J Hepatobiliary Pancreat Sci. 2018;25(1):5572. https://doi.org/10.1002/jhbp.516

3. Hatzidakis AA, Prassopoulos P, Petinarakis I, Sanidas E, Chrysos E, Chalkiadakis G, et al. Acute cholecystitis in high-risk patients: percutaneous cholecystostomy vs conservative treatment. Eur Radiol. 2002;12(7):1778-84. https://doi.org/10.1007/s00330001-1247-4

4. Yokoe M, Hata J, Takada T, Strasberg SM, Asbun HJ, Wakabayashi G, et al. Tokyo Guidelines 2018: diagnostic criteria and severity grading of acute cholecystitis (with videos). J Hepatobiliary Pancreat Sci. 2018;25(1):41-54. https://doi.org/10.1002/jhbp.515
Loozen et al. reported that the rate of recurrent episodes was $22 \%$, whereas other studies report rates ranging from $3 \%$ to $47 \%$. In our study, the rate was $5.5 \%$. This difference is attributed to the different acute episode definition made by each study. While some studies recorded every gallstone-related complication as an acute episode, most studies, like our study, recorded acute calculous cholecystitis episode as an episode ${ }^{19}$.

One of the three non-surviving patients died one day after PCT placement. It is controversial whether there is a true mortality rate for $\mathrm{PC}$, as $\mathrm{PC}$ was performed after this patient developed permanent septic shock ${ }^{20}$. We believe that it was too late to administer PC to the patient.

Due to its retrospective design, the benefits of our study are limited. PC is a promising method considering the CHOCOLATE $^{21}$ trial, which found no difference in mortality rates and showed a lower rate of major complications in PC when compared the outcomes of high-risk acute cholecystitis patients treated with either laparoscopic cholecystectomy or PC.

\section{CONCLUSIONS}

Approximately two-thirds of the recurrent episodes were observed in patients who underwent PCT before 21 days. There was a significant correlation between the timing of $<21$ days for catheter removal and experiencing a recurrent episode of acute cholecystitis.

\section{AUTHORS' CONTRIBUTIONS}

SAK: Conceptualization, Data curation, Writing - original draft, Writing - review \& editing. MT: Conceptualization, Data curation, Writing - review \& editing.

5. McGillicuddy EA, Schuster KM, Barre K, Suarez L, Hall MR, Kaml GJ, et al. Non-operative management of acute cholecystitis in the elderly. Br J Surg. 2012;99(9):1254-61. https://doi.org/10.1002/ bjs.8836

6. Bagla P, Sarria JC, Riall TS. Management of acute cholecystitis. Curr Opin Infect Dis. 2016;29(5):508-13. https://doi.org/10.1097/ QC0.0000000000000297

7. Pisano M, Allievi N, Gurusamy K, Borzellino G, Cimbanassi S, Boerna D, et al. 2020 World Society of Emergency Surgery updated guidelines for the diagnosis and treatment of acute calculus cholecystitis. World J Emerg Surg. 2020;15(1):61. https://doi. org/10.1186/s13017-020-00336-x

8. Gomi H, Solomkin JS, Schlossberg D, Okamoto K, Takada T, Strasberg SM, et al. Tokyo Guidelines 2018: antimicrobial therapy for acute cholangitis and cholecystitis. J Hepatobiliary Pancreat Sci. 2018;25(1):3-16. https://doi.org/10.1002/jhbp.518 
9. Wise JN, Gervais DA, Akman A, Harisinghani M, Hahn PF, Mueller PR. Percutaneous cholecystostomy catheter removal and incidence of clinically significant bile leaks: a clinical approach to catheter management. AJR Am J Roentgenol. 2005;184(5):1647-51. https://doi.org/10.2214/ajr.184.5.01841647

10. Macchini D, Degrate L, Oldani M, Leni D, Padalino P, Romano F, et al. Timing of percutaneous cholecystostomy tube removal: systematic review. Minerva Chir. 2016;71(6):415-26. PMID: 27280869

11. Wang $\mathrm{CH}$, Wu CY, Yang JC, Lien WC, Wang HP, Liu KL, et al. Long-term outcomes of patients with acute cholecystitis after successful percutaneous cholecystostomy treatment and the risk factors for recurrence: a decade experience at a single center. PLoS One. 2016;11(1):e0148017. https://doi.org/10.1371/journal. pone.0148017

12. Bhatt MN, Ghio M, Sadri L, Sarkar S, Kasotakis G, Narsule C, et al. Percutaneous cholecystostomy in acute cholecystitis-predictors of recurrence and interval cholecystectomy. J Surg Res. 2018;232:53946. https://doi.org/10.1016/j.jss.2018.06.051

13. Griniatsos J, Petrou A, Pappas P, Revenas K, Karavokyros I, Michail OP, et al. Percutaneous cholecystostomy without interval cholecystectomy as definitive treatment of acute cholecystitis in elderly and critically ill patients. South Med J. 2008;101(6):58690. https://doi.org/10.1097/SMJ.0b013e3181757b77

14. Simorov A, Ranade A, Parcells J, Shaligram A, Shostrom V, Boilesen E. Emergent cholecystostomy is superior to open cholecystectomy in extremely ill patients with acalculous cholecystitis: a large multicenter outcome study. Am J Surg. 2013;206(6):935-40;discussion 940-1. https://doi.org/10.1016/j.amjsurg.2013.08.019

15. Morse BC, Smith JB, Lawdahl RB, Roettger RH. Management of acute cholecystitis in critically ill patients: contemporary role for cholecystostomy and subsequent cholecystectomy. Am Surg. 2010;76(7):708-12. https://doi. org/10.1177/000313481007600724

16. Bundy J, Srinivasa RN, Gemmete JJ, Shields JJ, Chick JFB. Percutaneous cholecystostomy: long-term outcomes in 324 patients. Cardiovasc Intervent Radiol. 2018;41(6):928-34. https:// doi.org/10.1007/s00270-018-1884-5

17. Hsieh YC, Chen CK, Su CW, Chan CC, Huo TI, Liu CJ, etal. Outcome after percutaneous cholecystostomy for acute cholecystitis: a single-center experience. J Gastrointest Surg. 2012;16(10):1860-8. https://doi.org/10.1007/s11605-012-1965-8

18. Di Martino M, Mesa DM, González JML, Rodríguez ÁH, Martín-Pérez E. Safety of percutaneous cholecystostomy early removal: a retrospective cohort study. Surg Laparosc Endosc Percutan Tech. 2020;30(5):410-5. https://doi.org/10.1097/ SLE.0000000000000799

19. Loozen CS, Oor JE, van Ramshorst B, van Santvoort HC, Boerma D. Conservative treatment of acute cholecystitis: a systematic review and pooled analysis. Surg Endosc. 2017;31(2):504-15 https://doi.org/10.1007/s00464-016-5011-x

20. Charrier T, Kepenekian V, Muller A, Valette PJ, Glehen O, Cotte E, et al. Management after percutaneous cholecystostomy: what should we do with the catheter? Surg Laparosc Endosc Percutan Tech. 2018;28(4):256-60. https://doi.org/10.1097/ SLE.0000000000000559

21. Loozen CS, van Santvoort HC, van Duijvendijk P, Besselink MG, Gouma DJ, Nieuwenhuijzen GA, etal. Laparoscopic cholecystectomy versus percutaneous catheter drainage for acute cholecystitis in high risk patients (CHOCOLATE): multicentre randomised clinical trial. BMJ. 2018;363:k3965. https://doi.org/10.1136/bmj.k3965 